\title{
Carbon Capture and Storage across Fuels and Sectors in Energy System Transformation Pathways
}

\author{
Matteo Muratori ${ }^{a,}{ }^{,}$, Haroon Kheshgi ${ }^{b}$, Bryan Mignone $^{b}$, Leon Clarke ${ }^{a}$, Haewon McJeon $^{a}$, Jae Edmonds ${ }^{a}$ \\ ${ }^{a}$ Pacific Northwest National Laboratory - Joint Global Change Research Institute, 5825 University \\ Research Court, College Park, MD, 20740 \\ ${ }^{*}$ Corresponding Author. Present Position: National Renewable Energy Laboratory \\ matteo.muratori@nrel.gov (303)275-2927 \\ ${ }^{\mathrm{b}}$ ExxonMobil Research and Engineering Company, 1545 Route 22 East Annandale, NJ 08801
}

\begin{abstract}
Carbon capture and storage (CCS) is broadly understood to be a key mitigation technology, yet modeling analyses provide different results regarding the applications in which it might be used most effectively. Here we use the Global Change Assessment Model (GCAM) to explore the sensitivity of CCS deployment across sectors and fuels to future technology cost assumptions. We find that CCS is deployed preferentially in electricity generation or in liquid fuels production, depending on CCS and biofuels production cost assumptions. We consistently find significant deployment across both sectors in all of the scenarios considered here, with bioenergy with CCS (BECCS) often the dominant application. As such, this study challenges the view that CCS will primarily be coupled with power plants and used mainly in conjunction with fossil fuels, and suggests greater focus on practical implications of significant CCS and BECCS deployment to inform energy system transformation scenarios over the $21^{\text {st }}$ century.
\end{abstract}

\section{Keywords}

Carbon Capture and Storage; CCS; Biofuels; Climate Change Mitigation; Energy Systems; Transformation Pathways.

(C) 2016. This manuscript version is made available under the Elsevier user license http://www.elsevier.com/open-access/userlicense/1.0/ 


\section{Introduction}

Stabilizing atmospheric greenhouse gas (GHG) concentrations implies a transformation of the global energy system, including widespread deployment of low- or zero-carbon technologies. For over a decade, modeling studies using integrated assessment models (IAMs) have made the case that deployment of carbon capture and storage (CCS) technologies increases the feasibility and decreases the mitigation costs associated with deep GHG reduction goals [1, 2]. For example, among the 11 models that attempted to run scenarios without CCS in the EMF-27 study, only four were able to produce scenarios achieving radiative forcing goals of $2.6 \mathrm{~W} / \mathrm{m}^{2}$ by 2100 [1]. Scenarios generated by IAMs that reach these goals without CCS entail substantially higher climate change mitigation costs than scenarios from the same models that include CCS [3]. Recent studies have emphasized the role of bioenergy coupled with CCS (BECCS), as opposed to fossil fuels coupled with CCS [4]. BECCS could yield net negative emissions by effectively removing $\mathrm{CO}_{2}$ from the atmosphere and sequestering it, and it is often widely deployed in scenarios of deep GHG reduction $[4,5,6,7]$.

While the potential value of CCS is well established, the ultimate application for the technology - the sectors in which it deploys and the fuels with which it is associated - is not. The most recent IPCC assessment report stated that, "in the long term, the largest market for CCS systems is most likely found in the electric power sector" [8]. Yet, other studies have shown that CCS, particularly in conjunction with bioenergy, could be a valuable contributor in the liquid fuels sector. For example, Luckow et al. [9] show that in deep GHG reduction scenarios, BECCS is deployed in liquid fuels production as well as in electricity generation, two sectors that have significant GHG emissions, and thus sectors that can potentially provide significant climate change mitigation.

This uncertainty regarding the most appropriate future applications for CCS stems in part from the fact that, while multiple studies have highlighted the importance of CCS - and BECCS in particular - in achieving deep GHG reductions, the factors controlling the deployment of CCS across sectors and fuels has not been systemically explored. Studies such as EMF-27 have largely ignored variations in the cost and performance of CCS and have focused instead on the implications of having or not having CCS available in any form and on differences in model behavior.

In this paper, we examine the application of CCS across sectors and fuels in a single IAM. We focus on two important drivers of this outcome: uncertainty in future CCS technology costs and uncertainty in biofuels production costs. We find that the sector in which CCS is preferentially deployed (electricity generation or liquid fuels production) varies directly with these assumed technology costs. Nevertheless, across the range of technology cost assumptions and $\mathrm{CO}_{2}$ mitigation pathways considered here, we consistently find that CCS deploys significantly across both sectors, with the dominant share often in conjunction with bioenergy, rather than with fossil fuels. We provide an explanation for this result in terms of the costs of competing technologies, showing that BECCS always becomes cost-competitive when the carbon price is sufficiently high, due to its assumed net negative emissions, and discuss the implications for future research on energy transformation pathways.

\section{Methods}

\subsection{Potential Applications for CCS Technologies}

Carbon capture and storage technologies could potentially be used in a variety of existing and future industries and applications, including: natural gas processing; hydrogen and chemicals production; production of materials such as iron and cement; production of liquid fuels; and electricity generation. However, CCS technologies have not yet been broadly deployed commercially. Historically, CCS has been used in the gas processing industry, especially coupled to enhanced oil recovery (EOR) applications [10]. In the United States, where EOR is most widely employed, around 60 $\mathrm{Mt}$ of $\mathrm{CO}_{2}$ per year are currently used for EOR applications [11]. Other industrial applications, such as production of iron, steel, chemicals, or cement, have also been proposed for CCS, given the nature of the processes used, which could provide for economically competitive use of CCS.

However, industrial processes currently account for less than $20 \%$ of global $\mathrm{CO}_{2}$ direct emissions (i.e., emissions from direct combustion or use of fossil fuels, not including, for example, emissions from electricity used by industry) [12], and CCS might only be amenable to a fraction of this. While these sectors may serve as early applications of CCS and could promote technology development, deployment of CCS technologies at a scale that contributes significantly to climate change mitigation over the $21^{\text {st }}$ century requires deployment in sectors with greater $\mathrm{CO}_{2}$ emissions. These include the electric power sector as well as the liquid fuels production sector (if there is a large expansion of biofuel production). In the electricity sector, CCS technologies can be coupled to a variety of technologies, using fossil or bio- 
energy, and relative costs will be an important factor in their deployment. Similarly, CCS technologies can be coupled to the production of liquid fuels in a variety of different processes, as summarized in Figure 1.

The most appropriate applications for CCS in liquid fuels production is an important consideration for future energy system transformation pathways. For petroleum-based fuels, currently the dominant type of transportation fuel, about $7 \%$ of the crude oil energy content is used for fuel processing (refining of crude oil), and thus could potentially be captured. The remaining energy, and related emissions, are associated with the fuel combusted on-board vehicles and are not suitable for capture. This greatly limits the climate change mitigation potential of CCS coupled to petroleum-based fuels production. By contrast, production of liquid fuel from other sources requires much more energy than petroleum-based fuels, with coal-to-liquid conversion leading to significantly higher $\mathrm{CO}_{2}$ emissions. $\mathrm{CCS}$ technologies could reduce this gap, making coal-based liquids comparable to petroleum-based fuels in terms of total emissions (process and combustion emissions), but such substitution would not reduce overall $\mathrm{CO}_{2}$ emissions from current levels.

Production of ethanol (EtOH) from corn also requires a significant amount of energy. Today this energy primarily comes from fossil fuels, and CCS technologies could be used to capture some of the associated emissions. In addition, $\mathrm{CO}_{2}$ produced during fermentation, which accounts for a portion of the life cycle emissions and is easier to capture than combustion flue streams [13], could also be captured, further reducing total emissions. Cellulosic ethanol and Fischer-Tropsch biofuels, while not widely available today, could potentailly be produced with almost no use of fossil energy. These biofuels are estimated to have low net emissions without CCS, assuming biomass is grown with no landuse-related emissions, and could potentially lead to net-negative emissions if coupled to CCS. Because of the greater mitigation potential of cellulosic ethanol and Fischer-Tropsch biofuels, these biofuel options are a key focus of the remainder of this paper.

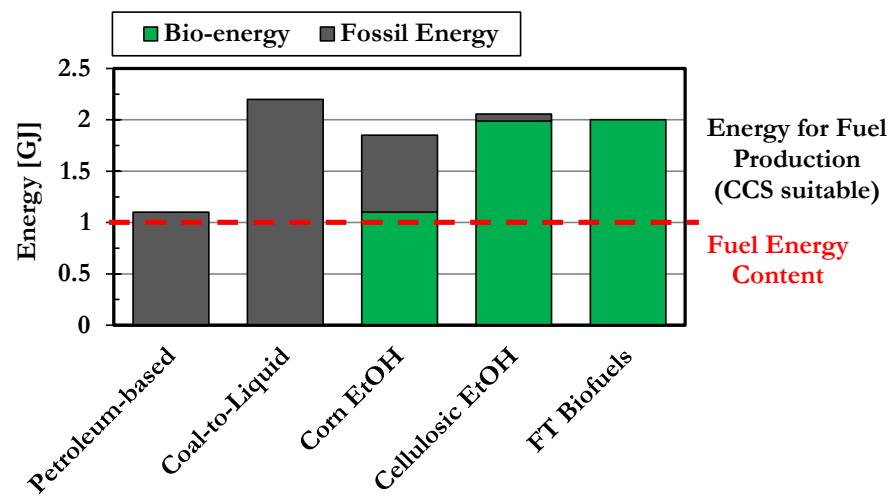

Figure 1. Energy content and energy consumed in the production of liquid fuels. The red line $(=1)$ indicates the energy that ends up in the fuel itself. Everything above the red line is the energy required for the production of the fuel. Only the emissions associated with large stationary sources of $\mathrm{CO}_{2}$ are potentially suitable to be captured with CCS technologies, and these are approximately the emissions above the red line, with those below the red line coming from small and mobile sources.

For industrial applications, and production of liquid fuels, the production schedule is not dictated by the demand system, while electricity production must match demand in every instant, following seasonal patterns and daily fluctuations [14]. This reduces the constraints on the operation of CCS systems in these sectors, since the main industrial output (e.g. liquid fuel) can be more easily stored.

\subsection{The Global Change Assessment Model}

The Global Change Assessment Model (GCAM) is a community integrated assessment model (IAM) developed and maintained by Pacific Northwest National Laboratory at the Joint Global Change Research Institute [15]. GCAM is a dynamic-recursive economic model driven by assumptions about population and labour productivity that determine potential gross domestic product at 5 year time steps. It includes technology-rich representations of the economy, energy sector, and land use. GCAM is global in scope and the energy and economic systems are disaggregated into 32 
geopolitical regions, explicitly linked through international trade in energy commodities, agricultural and forest products, and other goods and emissions permits. 283 land regions are included in the model. GCAM is linked to a climate model of intermediate complexity that can be used to explore climate change mitigation policies including carbon taxes, carbon trading, regulations, and accelerated deployment of energy technology.

GCAM includes detailed information on availability of different primary energy resources in each region of the world, including supply curves for renewable energy sources, uranium, and fossil fuels. Various extraction methods (e.g. underground and surface mining), resources type (e.g. conventional and unconventional crude oil) and technologies (e.g. natural gas simple and combined cycles) are considered. Energy demand and supply are computed in each region and in each time-step, and the energy conversion processes needed to produce the final energy carriers - used to deliver energy services - are explicitly modelled. GCAM considers six different final energy carriers: liquid fuels, electricity, pipeline gas, coal, bioenergy, and hydrogen. Competition among different primary energy sources is modelled for different energy conversion processes. For example, oil, coal, natural gas, and biomass, all traded globally in GCAM, compete as possible inputs for the production of liquid fuels using a logit formulation [16]. Analogously, renewables, nuclear, and fossil fuels compete for electricity generation. Several CCS technologies are modelled in GCAM, including industrial applications (e.g. cement and fertilizer production), production of hydrogen, and production of electricity or liquid fuels from coal, petroleum, natural gas, and biomass.

Emissions of greenhouse gases, aerosols, and short-lived species linked to human activities are computed endogenously in GCAM. Terrestrial carbon emissions in GCAM are derived from the detailed land-use-land-cover model. Montreal gases are treated exogenously with emissions set at levels specified by the relevant international agreements. In this paper we use the release version 4.2 of GCAM. GCAM computes land use and land use change emissions associated with each scenario. However, such emissions are not explicitly priced in climate change mitigation scenarios studied here, because pricing terrestrial carbon would lead to significant, and potentially unrealistic, terrestrial carbon mitigation by incentivizing afforestation [17]. Rather, land-protection is implemented in GCAM that limits human use of forests and/or other unmanaged ecosystems for biomass cultivation (or other mitigation options, such as afforestation). However, any land use change emissions associated with bioenergy production are included in the calculation of total emissions [18].

\subsection{Scenario Construction}

We use GCAM [15] to simulate two climate change mitigation scenarios: RCP 4.5 [19] and RCP 2.6 [20], under a range of different assumptions about CCS and bioenergy costs. These scenarios, proposed by Moss et al. [21] and largely adopted by the IPCC and the integrated assessment modeling community, are intended to stabilize radiative forcing below 4.5 and $2.6 \mathrm{~W} / \mathrm{m}^{2}$ relative to pre-industrial values, which according to the IPCC, would likely (>66\% chance) maintain the global average temperature increase relative to preindustrial levels below $3^{\circ} \mathrm{C}$ and $2^{\circ} \mathrm{C}$, respectively [22]. Global $\mathrm{CO}_{2}$ emissions pathways for the RCP 4.5 and RCP 2.6 scenarios are shown in Figure 7 in the supplemental material. To match these $\mathrm{CO}_{2}$ emission pathways, an increasing carbon price is applied to fossil fuel and industrial $\mathrm{CO}_{2}$ emissions and to non- $\mathrm{CO}_{2}$ greenhouse gases. An important feature of the RCP 2.6 scenario is that it does not rely on extensive net negative global $\mathrm{CO}_{2}$ emissions in the second half of the century. A number of recent papers have raised questions about the institutional limitations of net negative emissions and the realism of scenarios that reach the targeted end-of-the-century $\mathrm{CO}_{2}$ concentration with relatively small emissions reductions in the first half of the century followed by deeply negative $\mathrm{CO}_{2}$ emissions in the second half of the century [7, 23, 24, 25].

\subsubsection{Initial Costs Assumptions}

Many aspects of carbon capture and storage technologies are uncertain. Figure 2, for example, reports a summary of recent (post-2010) estimates of efficiency and cost for $n^{\text {th }}$-of-a-kind coal-fired and natural gas power plants equipped with post-combustion CCS, showing variations across studies due to both technological and geographical factors. 

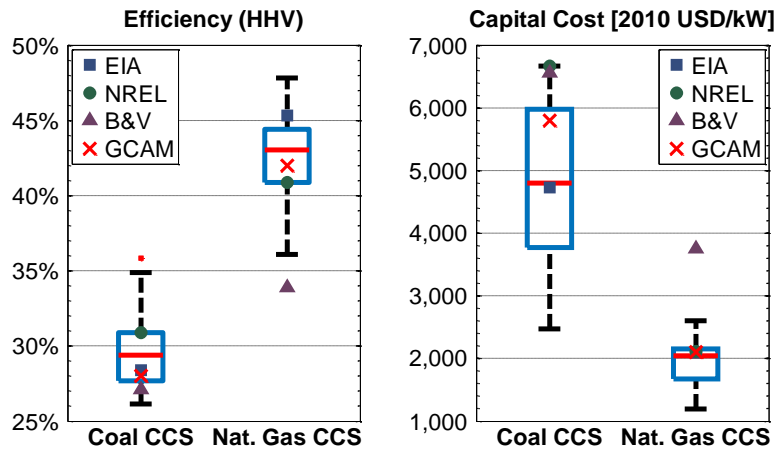

Figure 2. Efficiency and capital costs of $n^{\text {th }}$-of-a-kind coal-fired and natural gas combined cycle power plants equipped with post-combustion CCS in 2020. The boxplots include estimates from several sources available in the open literature. GCAM assumptions and three main sources are reported explicitly for deployment in the USA: EIA: [26]; NREL:[27] ; B\&V: [28].

Similarly, the costs of producing biofuels coupled with CCS are uncertain. In 2009 a comprehensive National Academy of Sciences study [29] reported non-energy cost (i.e. not including the cost of the biomass feedstock) for producing a barrel of cellulosic ethanol of about $\$ 30$. Producing liquid fuels from biomass using thermochemical conversion was reported to cost $\$ 68$ per barrel, increasing to $\$ 75$ if CCS technologies were used. More recent estimates report nonenergy costs about twice as high [30, 31, 32, 33].

We assume that CCS technologies become available in 2020, at the costs reported in Table 1 for power plants and Table 2 for liquid fuels production plants. Cost for CCS equipped power plants are estimated by synthesizing information from several studies [26] [27] [28] [34]. Costs of biofuel production are taken from detailed NREL studies for cellulosic ethanol [30,31], and recent DOE studies for FT biofuels [32, 33]. CCS cost adders for liquid fuels production are taken from Dooley and Dahowskiet al. [35]. Transportation and storage costs for CCS technologies are modeled in GCAM based on detailed regional supply curves [36] and are not included in the costs reported in Tables 1 and 2 .

Table 1. Technology cost and performance assumptions for CCS-equipped power plants in 2020 (costs are expressed in 2010 USD). $\mathrm{CO}_{2}$ avoided costs refer to a specific plant compared to new-build coal-fired steam plants all in base-load operation. Fuel costs are assumed to be: $\mathbf{\$ 2 . 2 8 / G J}$ (\$60/tonne) for coal; $\$ 7.1 / \mathrm{GJ}$ (\$7.5/MBTU) for natural gas; $\$ 11.6 / \mathrm{GJ}$ (\$65/bbl) for oil; and $\$ 5 / \mathrm{GJ}$ (\$90/dry tonne) for biomass. $\mathrm{CO}_{2}$ transport and storage cost are not included in the costs reported in this table.

\begin{tabular}{|c|c|c|c|c|c|}
\hline & $\begin{array}{l}\text { Capital Cost } \\
{[\$ / k W]}\end{array}$ & $\begin{array}{c}\text { Efficiency } \\
{[\%]}\end{array}$ & $\begin{array}{c}\mathrm{CO}_{2} \text { Capture } \\
{[\%]}\end{array}$ & $\begin{array}{c}\mathrm{CO}_{2} \text { Capture Cost } \\
{\left[\$ / \text { ton } \mathrm{CO}_{2}\right]}\end{array}$ & $\begin{array}{c}\mathrm{CO}_{2} \text { Avoided } \\
\text { Cost } \\
{\left[\$ / \text { ton } \mathrm{CO}_{2}\right]}\end{array}$ \\
\hline Coal (steam plant) & 2,900 & $38 \%$ & - & - & - \\
\hline Coal (steam plant) + CCS & 5,800 & $28 \%$ & $90 \%$ & 63 & 88 \\
\hline Coal (IGCC) & 4,000 & $39 \%$ & - & - & - \\
\hline Coal (IGCC) + CCS & 6,600 & $32 \%$ & $90 \%$ & 61 & 106 \\
\hline Natural Gas (CC) & 1,050 & $52 \%$ & - & - & - \\
\hline Natural Gas (CC) + CCS & 2,100 & $42 \%$ & $90 \%$ & 91 & 33 \\
\hline Oil (CC) & 1,050 & $51 \%$ & - & - & - \\
\hline Oil $(C C)+C C S$ & 2,600 & $39 \%$ & $90 \%$ & 105 & 95 \\
\hline Biomass (steam plant) & 4,000 & $25 \%$ & - & - & - \\
\hline Biomass (steam plant) + CCS & 7,700 & $18 \%$ & $90 \%$ & 72 & 244 \\
\hline Biomass (IGCC) & 6,000 & $30 \%$ & - & - & - \\
\hline Biomass (IGCC) + CCS & 8,850 & $25 \%$ & $90 \%$ & 66 & 242 \\
\hline
\end{tabular}


Table 2. Technology cost and performance assumptions for liquid fuels production plants in 2020 (cost are expressed in 2010 USD). $\mathrm{CO}_{2}$ avoided costs refer to a specific fuel compared to petroleum- based fuel. Non-energy costs and $\mathrm{CO}_{2}$ capture efficiencies are reported as ranges, since different $\mathrm{CO}_{2}$ streams can be captured at different cost levels [35]. Fuel costs are assumed to be: $\$ 2.28 / G J$ ( $\$ 60 /$ tonne) for coal; $\$ 7.1 / G J$ (\$7.5/MBTU) for natural gas; $\$ 11.6 / G J$ (\$65/bbl) for oil; and $\$ 5 / G J$ (\$90/dry tonne) for biomass. $\mathrm{CO}_{2}$ transport and storage cost are not included in the costs reported in this table.

\begin{tabular}{lccccc}
\hline & $\begin{array}{c}\text { Non-Energy Cost } \\
{[\$ / \text { boe }]}\end{array}$ & $\begin{array}{c}\text { Efficiency } \\
{[\%]}\end{array}$ & $\begin{array}{c}\mathrm{CO}_{2} \text { Capture } \\
{[\%]}\end{array}$ & $\begin{array}{c}\mathrm{CO}_{2} \text { Capture Cost } \\
{\left[\$ / \text { tonCO }_{2}\right]}\end{array}$ & $\left.\begin{array}{c}\mathrm{CO}_{2} \text { Avoided Cost } \\
{[\$ / \text { tonCO }}\end{array}\right]$
\end{tabular}

The cost of $\mathrm{CO} 2$ captured $(\$ / \mathrm{tCO} 2)$ is computed by dividing the incremental cost of producing electricity or liquid fuels with a CCS-equipped plant $(\$ / \mathrm{kWh}, \$ /$ boe $)$ by the amount of CO2 captured. The cost of $\mathrm{CO} 2$ captured represents the minimum $\mathrm{CO} 2$ plant gate sales price that would incentivize carbon capture in lieu of a corresponding non-capture plant based on the same technology.

The cost of $\mathrm{CO}_{2}$ avoided $\left(\$ / \mathrm{tCO}_{2}\right)$, on the other hand, represents the minimum $\mathrm{CO}_{2}$ emissions price that would, when applied to both the capture and non-capture plants, incentivize carbon capture in lieu of a defined reference plant without CCS. This is computed as the ratio of the difference between total production costs $(\$ / \mathrm{kWh}, \$ / \mathrm{boe})$ of a plant equipped with CCS and a reference plant and the difference between the related $\mathrm{CO}_{2}$ emissions $\left(\mathrm{tCO}_{2} / \mathrm{kWh}, \mathrm{tCO}_{2} /\right.$ boe $)$. The bioenergy $\mathrm{CO}_{2}$ costs reported in Table 1 and Table 2 do not include land-use carbon sinks.

\subsubsection{Future Cost Trajectories}

Starting from the technology cost assumptions above for 2020, we explore future technology cost uncertainty by applying different improvement rates over time to CCS technologies coupled to power plants and biofuel production facilities. Specifically, we consider 3 scenarios of cost reduction for CCS technologies (applied to the CCS component of total capital or non-energy cost): no improvement, moderate technology improvement (reaching $60 \%$ of the initial cost by 2100), and rapid technology improvement (reaching $30 \%$ of the initial cost by 2100 ). These cost reduction pathways are shown in Figure 8 in the supplemental material. Similarly, we explore the uncertainty related to biofuel production costs by applying the same technology improvement pathways used to simulate CCS cost improvements to the non-energy costs of biofuels production. Combining these different pathways for CCS and biofuels production costs yields a matrix of nine scenarios. The reviewed literature does not suggest which technology is more likely to achieve significant cost reductions, if any, and thus we do not assign likelihoods to any of the scenarios. The cost trajectories assumed here bound trajectories of future cost evolution considered by other studies, such as a recent assessment by Rubin et al. [37].

It is important to note that the cost of producing biofuels with CCS relative to the cost of producing oil-based fuels is determined more by the biomass processing cost (i.e. the conversion of biomass to a biofuel) than the CCS cost adder, which is $6-44 \%$ of the biofuel production cost in GCAM. By contrast, the CCS cost adders are responsible for total capital cost increases of up to $\sim 100 \%$ for CCS-equipped power plants in GCAM. This implies that the matrix of nine scenarios can be used to effectively isolate the effects of technology improvement in liquid fuels production (changing the biofuel non-energy cost) and in CCS-equipped electricity generation (changing the CCS cost adder, since this affects power plants more than liquid fuel production facilities in our scenarios).

Finally, the costs of competing technologies in GCAM (e.g. other power generation technologies such as renewables) also change over time at different rates, depending on technology maturity, bounded by the no improvement and rapid improvement scenarios reported in Figure 8. However, these cost trajectories do not change across the nine scenarios considered here, allowing us to isolate the implications of different assumptions about the cost evolution of CCS and biofuel production technologies. 


\section{Results and Discussion}

The deployment of CCS technologies in different sectors, as projected by integrated assessment models, is driven by a range of factors, including most importantly their assumed costs relative to alternatives with which they compete. However, there is uncertainty about the cost of CCS technologies, as well as about the production cost of biofuels. Therefore, in the remainder of this paper, we explore the uncertainty in technology costs for CCS-equipped power plants and biofuel production plants to illustrate possible future deployment scenarios for CCS.

Under both RCP 4.5 and RCP 2.6, the deployment of CCS technologies starts off in industrial applications, followed by deployment of CCS-equipped power plants and/or liquid fuel production facilities, depending on the technology cost pathway (see Figure 11 in the supplemental material). Some industrial sectors might serve as early-movers in the CCS industry given the lower cost of $\mathrm{CO}_{2}$ avoided in some industrial applications, which could drive CCS development and technology cost reduction. However, over the $21^{\text {st }}$ century, only electricity and liquid biofuels applications capture and store a sufficient amount of $\mathrm{CO}_{2}$ to contribute significantly to climate change mitigation in GCAM scenarios.

Figure 3 shows electricity and liquid fuels production by technology assuming moderately improving costs for both CCS and biofuel production technologies under both RCP 4.5 and RCP 2.6. In these scenarios, a ramp-up of CCS takes place in the first half of the century, with the bulk of CCS deployment occurring after 2050.
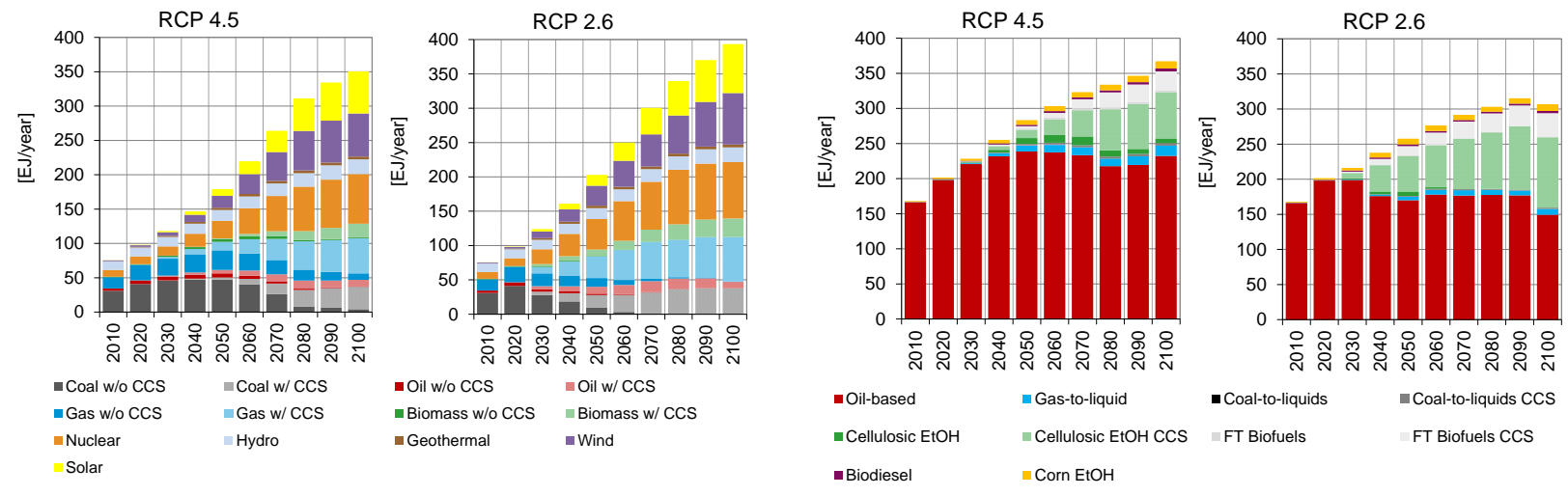

Figure 3. Global electricity generation (left) and liquid fuels production (right) by technology assuming moderately improving costs for both CCS and biofuel production technologies.

Under RCP 4.5, 500-1300 GW of CCS-equipped power plants are deployed by 2050 (generating 8-19\% of total electricity generation), sequestering 1.4-4.1 Gt CO 2 per year, depending on the technology cost assumptions (ranges represent the range of values across the matrix of nine cost pathways). Also by 2050, 3.6-17.2 Million barrels of oil equivalent per day of liquid fuels are produced using CCS technologies (3-13\% of total liquid fuel production), leading to an additional 0.5-3.5 Gt CO 2 sequestered per year. By 2100, CCS technologies are widely adopted, with up to $40 \%$ of total electricity and up to $35 \%$ of liquid fuels produced with CCS technologies, depending on the technology cost assumptions, leading to $152-240$ cumulative $\mathrm{GtCO}_{2}$ sequestered globally. Over $75 \%$ of total biofuels production in these scenarios is coupled to CCS by 2100 (whereas 30-55\% of biofuels production is coupled to CCS by 2050 ).

Under RCP 2.6, global $\mathrm{CO}_{2}$ emissions are reduced by two-thirds by 2050 relative to 2010, and deployment of CCS technologies is higher. By 2050, 2000-3400 GW of CCS-equipped power plants are deployed in the GCAM scenarios (generating $27-42 \%$ of total electricity), sequestering $7.1-13.5 \mathrm{Gt} \mathrm{CO}_{2}$ per year. Also 22.5-37.4 Million barrels of oil equivalent per day of liquid fuels are produced using CCS technologies in 2050 (20-31\% of total liquid fuel production), leading to an additional 4.8-8.5 $\mathrm{GtCO}_{2}$ sequestered per year. By 2100 , CCS technologies are widely adopted, with up to $42 \%$ of total electricity and up to $45 \%$ of liquid fuels produced with CCS technologies, depending on the technology cost assumptions, leading to 311-394 cumulative $\mathrm{GtCO}_{2}$ sequestered globally by 2100 . Nearly all biofuels produced in these scenarios are coupled to CCS by 2100 (whereas $70-90 \%$ of biofuels production is coupled to CCS by 2050 ).

\subsection{CCS Deployment by Sector}

In the scenarios considered here, CCS technologies are not only coupled to electricity generation but also to the production of biofuels across a range of technology cost assumptions and different levels of climate change mitigation. Figure 4 shows global cumulative (2020-2100) $\mathrm{CO}_{2}$ stored by sector, which illustrates how different 
technology cost assumptions affect the inter-sectoral deployment of CCS technologies. Movement upward along the $y$-axis is associated with a faster rate of assumed cost improvement over the century of the CCS portion of all technology costs in all sectors; movement rightward along the x-axis is associated with a faster rate of assumed improvement of all biofuel non-energy costs (see Figure 8 in supplemental material).

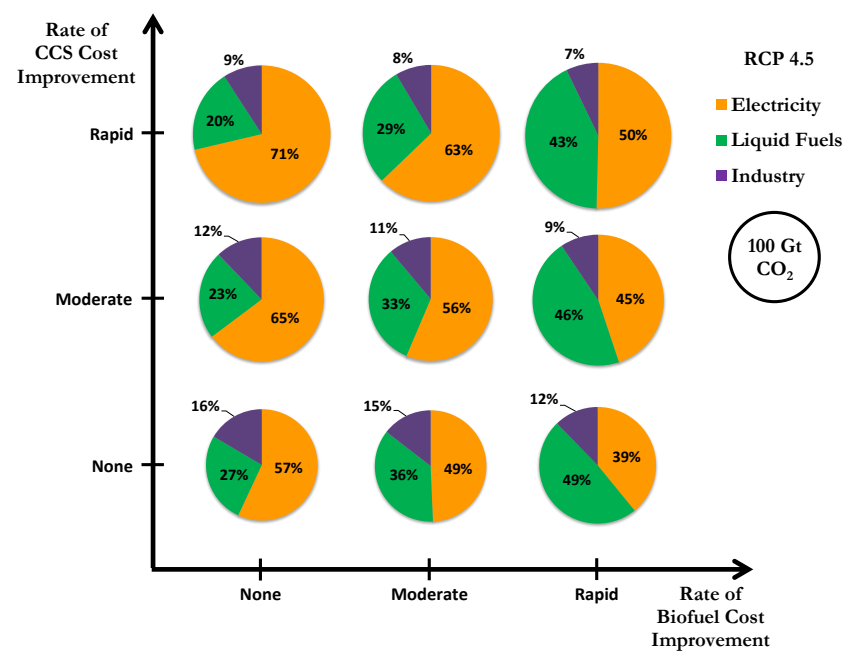

Figure 4. Global cumulative (2020-2100) $\mathrm{CO}_{2}$ stored across different sectors for different technology cost pathways under RCP 4.5.

In scenarios assuming no improvement in biofuel costs and rapid improvement in CCS costs, the deployment of CCS is predominantly in the electricity sector, since reducing the CCS cost reduces the total cost of relevant electricity generation technologies more than the total cost of biofuels with CCS. On the other hand, in scenarios assuming rapid improvement in biofuel production costs and no improvement in CCS costs, CCS technologies are used in biofuels production more than in any other sector, since total biofuels production costs are driven largely by the non-energy cost of biofuels production.

Increased mitigation stringency has a limited effect on the share of $\mathrm{CO}_{2}$ stored among sectors, but has a strong effect on the total $\mathrm{CO}_{2}$ stored, as shown by comparing Figure 4 to Figure 12 in the supplemental material. For a given level of climate change mitigation, less $\mathrm{CO}_{2}$ is stored in a high technology cost scenario (no cost improvement shown in the bottom-left pie in Figure 4) since other low-carbon technologies, such as nuclear and renewables, are more widely deployed. However, this effect is weaker under RCP 2.6 given a greater need to deploy all low-carbon technologies.

\subsection{CCS Deployment by Fuel}

CCS coupled with biomass becomes increasingly competitive as the carbon price increases because of the negative emissions resulting from the capture and storage of the $\mathrm{CO}_{2}$ contained in biomass. In the electricity sector, CCS technologies can be coupled to a variety of fuels, including coal, oil, natural gas, and biomass. When all sectors are considered, more $\mathrm{CO}_{2}$ is stored from biomass than any other fuel, a result that is consistent across both RCP scenarios and across the entire range of technology cost assumptions, as shown in Figure 5 and Figure 13 in the supplemental material.

The timing of BECCS deployment in different applications depends on the mitigation level. In the scenarios considered here, the use of BECCS in the electricity sector starts around 2050 under RCP 4.5. Under RCP 2.6, the carbon price is significantly higher, and BECCS is deployed as early as 2030. Production of cellulosic ethanol with CCS starts between 2030 and 2040 under RCP 4.5, and in 2030 under RCP 2.6. FT biofuels with CCS are produced starting in 2045 under RCP 4.5 scenarios and as early as 2035 under RCP 2.6. 


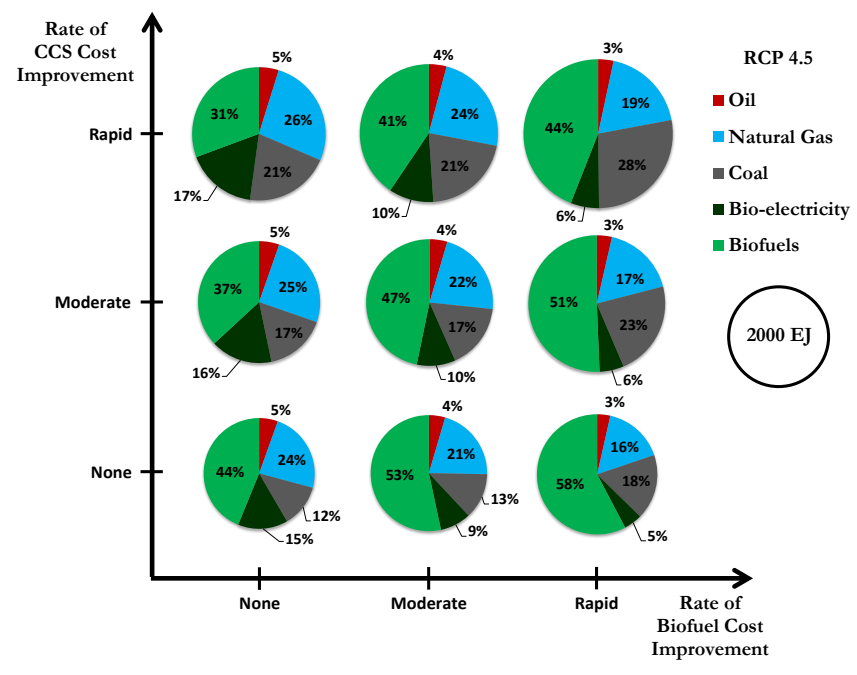

Figure 5. Global cumulative (2020-2100) primary energy from CCS technologies by fuel type for different technology cost pathways under RCP 4.5.

The fuel choice for CCS applications in the electricity sector in GCAM is driven by the levelized costs of electricity (LCOE), which depend on: $a$ ) technology cost (i.e. capital and O\&M cost) and performance (i.e. efficiency); $b$ ) fuel cost (i.e. coal, natural gas, oil, uranium, and biomass); and c) the price of carbon. Figure 6 illustrates the competition among different technologies for new-build electricity generation in base-load operation for ranges of assumed carbon and fuel prices. Kheshgi et al. [38] developed a similar chart that included nuclear power, but not bioelectricity. Absent any carbon price, and based on the assumptions in Table 1, the competition among different fuels in the electric sector reduces to a choice between coal-fired steam plants and natural gas-fired combined cycle plants, depending on the fuel cost. If a price on carbon is introduced, natural gas becomes more competitive, caeteris paribus, as a consequence of its lower carbon intensity. At a sufficiently high carbon price, CCS technologies become competitive for both coal and natural gas.

Over the range of parameters considered, biomass-fired power plants without CCS never have the lowest LCOE. For high carbon prices, however, biomass coupled to CCS has the lowest LCOE, due to revenues from the net negative $\mathrm{CO}_{2}$ emissions. The level at which biomass-fired steam plants with CCS become competitive depends on technology cost assumptions and on the biomass price. For the technology assumptions reported in Table 1, and for the current average biomass price in the United States (around \$3.5/GJ, although there is significant regional variation [39]), CCS would be coupled to biomass rather than natural gas or coal based on LCOE. For higher biomass prices, biomass-fired steam plants with CCS become competitive with fossil fuel-fired plants with CCS at a higher carbon price (Figure 14 in the supplemental material reports the biomass prices computed in GCAM for the moderate technology cost improvement scenarios). If CCS technologies are not available, biomass-fired power plants compete with natural gas combined cycle plants only at high carbon and natural gas prices, as shown in Figure 15 in the supplemental material. A similar result holds for the liquid fuels production sector, namely that at sufficiently high carbon prices, liquids derived from bioenergy coupled to CCS are more cost-effective than alternatives due to the assumed net negative emissions. The carbon prices required to deploy BECCS in both electricity and liquid fuels production are achieved during the $21^{\text {st }}$ century in both the RCP 4.5 and 2.6 scenarios (which explains why BECCS is observed in both sectors in both RCPs), but the required carbon prices are achieved somewhat later in RCP 4.5 than in RCP 2.6 (which explains the difference in the scale of cumulative BECCS deployment between the RCPs). 


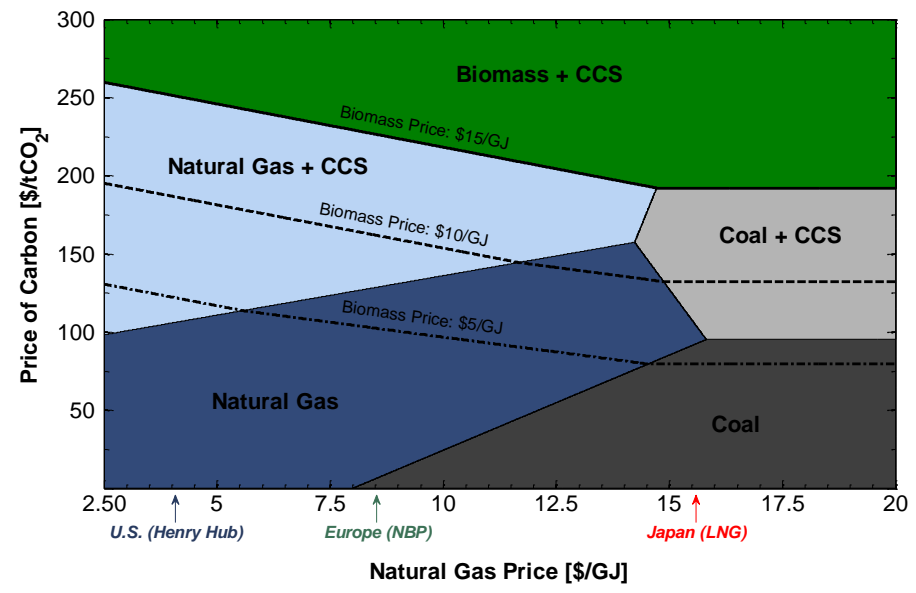

Figure 6. Economic competition between new-build natural gas, coal, and biomass for the generation of electricity in baseload operation over a range of carbon prices and fuel prices. Technology cost assumptions are reported in Table 1 in the supplemental material. The coal price is assumed to be constant at $\$ 2.28 / G J(\$ 60 /$ tonne). For biomass, $\$ 5$ corresponds to $\$ 90 /$ dry tonne. For comparison, EIA reports average wood and waste biomass prices for the commercial, industrial and electric power sectors of $\$ 3.5 / \mathrm{GJ}$ in 2014 in the United States [39]. $\mathrm{CO}_{2}$ transport and storage cost are not included in this figure.

\subsection{Comparison of Overall CCS and Bioenergy Deployment to Other Information}

Some outcomes of the scenarios considered in this study can be compared to other published estimates. For example, one point of comparison pertains to underground $\mathrm{CO}_{2}$ storage potential. Estimates of global storage capacity vary widely in the current literature, but the last assessment report of the IPCC reports that: "lack of geologic storage space is unlikely to be the primary impediment to CCS deployment" [8]. In particular, storage capacity estimates suggest that geological reservoirs alone could store several thousand Gt of carbon [2]. Put differently, sufficient potential for secure and accessible storage of captured $\mathrm{CO}_{2}$ appears to exist at the global level to meet demand over the $21^{\text {st }}$ century for the scenarios considered in this paper. However, some regions with limited storage capacity (e.g. some Asian countries) could approach their capacity limits, depending on what those limits turn out to be [40].

Another point of comparison pertains to global biomass supply. Global biomass use in the scenarios considered ranges from 79-145 EJ/year in 2050 under RCP 4.5 (257-287 EJ/year in 2100). Under RCP 2.6, global biomass use ranges from 195-228 EJ/year in 2050 (332-346 EJ/year in 2100). For comparison, a 2010 IEA study found that the technical potential of biomass in 2050 ranged from $250 \mathrm{EJ} /$ year to $500 \mathrm{EJ} /$ year [41], the upper bound of which is consistent with that reported by the IPCC Special Report on Renewable Energy [42]. While the amount of biomass used in 2050 in the scenarios presented in this paper is below other estimates of the technical potential of biomass supply, cultivating that amount would nevertheless involve large areas of land.

\section{Conclusions}

Prior integrated assessment research has emphasized the importance of CCS, and BECSS in particular, in scenarios of deep GHG reductions. However, these insights often follow from model comparison studies, such as EMF-27 [1, 4, 5, 6], which examine the sensitivity of model results to CCS availability in a rather coarse manner (by toggling the overall availability of CCS), rather than by exploring a range of cost trajectories and separately varying assumptions about CCS used in different sectors. Furthermore, when insights are extracted from model comparison studies, it is difficult to control for differences between models that may affect results regarding particular technologies. This study has attempted to address these gaps by exploring the sensitivity of future CCS deployment - the sectors in which it deploys and the fuels to which it is coupled - by systemically varying relevant technology costs in a single integrated assessment model.

CCS can significantly contribute to $\mathrm{CO}_{2}$ emissions reduction over the $21^{\text {st }}$ century only when largely deployed in conjunction with electricity generation from fossil fuels and biomass, or production of liquid biofuels. Some industrial 
applications with lower $\mathrm{CO}_{2}$ avoided costs could be early opportunities for CCS application, but their long-term role is limited by the total emissions from those sectors. This observation suggests that consideration of CCS applications needs to take into account not just the energy system that exists today and the current potential for CCS applications, such as applications in coal-fired electricity generation (see, for example $[8,43,44]$ ), but also how the energy system might evolve over the $21^{\text {st }}$ century when potential applications for CCS may be different than those that are apparent today.

Toward this end, our results show that the sector in which CCS preferentially deploys varies based on the assumed technology costs, which are characterized by significant uncertainty. Importantly, however, by using a consistent modeling framework, our findings illustrate for the first time that deployment of CCS across multiple sectors and in conjunction with bioenergy, as observed in prior studies, is a result that is robust to a wide range of cost assumptions for CCS and bioenergy. This study provides a simple explanation for these results in terms of the costs of competing technologies, showing that BECCS always becomes cost-competitive at a sufficiently high carbon price. Given that CCS, and BECCS in particular, are likely to be widely deployed in future scenario studies, we conclude that future research on energy transformation pathways should focus more heavily on the practical implications of widespread CCS and BECCS deployment to evaluate feasibility, which in turn can improve integrated assessment models and enhance the realism of scenarios produced by such models. 


\section{Acknowledgements}

The PNNL authors are grateful for research support provided by ExxonMobil Research and Engineering Company. The Pacific Northwest National Laboratory is operated for DOE by Battelle Memorial Institute under contract DE-AC0576RL01830. The views and opinions expressed in this paper are those of the authors alone.

\section{References}

[1] V. Krey, G. Luderer, L. Clarke, and E. Kriegler, "Getting from here to there-energy technology transformation pathways in the EMF27 scenarios," Climatic change, vol. 123, no. 3-4, pp. 369-382, 2014.

[2] Clarke, $\mathrm{L}$ and Jiang, $\mathrm{K}$ and Akimoto, $\mathrm{K}$ and Babiker, $\mathrm{M}$ and Blanford, $\mathrm{G}$ and Fisher, $\mathrm{K}$ and Vanden, J and Hourcade, JC and Krey, V and Kriegler, E and Löschel, A and McCollum, D and Paltsev, S and Rose, S and Shukla, P.R. and Tavoni, M and van der Zwaan, BCC and van Vuuren, D, "Assessing Transformation Pathways. In: Climate Change 2014: Mitigation of Climate Change. Contribution of Working Group III to the Fifth Assessment Report of the Intergovernmental Panel on Climate Change" 2014.

[3] O. Akashi, T. Hanaoka, T. Masui, and M. Kainuma, "Halving global GHG emissions by 2050 without depending on nuclear and CCS," Climatic Change, pp. 1-12, 2014.

[4] S. K. Rose, E. Kriegler, R. Bibas, K. Calvin, A. Popp, D. P. van Vuuren, and J. Weyant, "Bioenergy in energy transformation and climate management," Climatic Change, vol. 123, no. 3-4, pp. 477-493, 2014.

[5] B. S. Koelbl, M. A. van den Broek, A. P. Faaij, and D. P. van Vuuren, "Uncertainty in Carbon Capture and Storage (CCS) deployment projections: a cross-model comparison exercise," Climatic Change, vol. 123, no. 3-4, pp. 461-476, 2014.

[6] J. van Vliet, A. F. Hof, A. M. Beltran, M. van den Berg, S. Deetman, M. G. den Elzen, P. L. Lucas, and D. P. van Vuuren, "The impact of technology availability on the timing and costs of emission reductions for achieving long-term climate targets," Climatic Change, vol. 123, no. 3-4, pp. 559-569, 2014.

[7] M. Muratori, K. Calvin, M. Wise, P. Kyle, and J. Edmonds, "Global economic consequences of deploying bioenergy with carbon capture and storage (BECCS)," Environmental Research Letters, vol. 11, no. 9, p. 095004, 2016.

[8] Bruckner T, I. A. Bashmakov, Y. Mulugetta, H. Chum, A. de la Vega Navarro, J. Edmonds, A. Faaij, B. Fungtammasan, A. Garg, E. Hertwich, D. Honnery, D. Infield, M. Kainuma, S. Khennas, S. Kim, H. B. Nimir, K. Riahi, N. Strachan, R. Wiser, and X. Zhang, "Energy Systems. In: Climate Change 2014: Mitigation of Climate Change. Contribution of Working Group III to the Fifth Assessment Report of the Intergovernmental Panel on Climate Change" 2014.

[9] P. Luckow, M. A. Wise, J. J. Dooley, and S. H. Kim, "Large-scale utilization of biomass energy and carbon dioxide capture and storage in the transport and electricity sectors under stringent $\mathrm{CO}_{2}$ concentration limit scenarios," International Journal of Greenhouse Gas Control, vol. 4, no. 5, pp. 865-877, 2010.

[10] V. Alvarado and E. Manrique, "Enhanced oil recovery: an update review," Energies, vol. 3, no. 9, pp. 1529-1575, 2010.

[11] Matt Wallace, Vello Kuuskraa, and Phil DiPietro. Prepared by Energy Sector Planning and Analysis (ESPA) for the United States Department of Energy (DOE), National Energy Technology Laboratory (NETL), Near-Term Projections of $\mathrm{CO}_{2}$ Utilization for Enhanced Oil Recovery. DOE/NETL-2014/1648, April 7, 2014.

[12] IEA STATISITCS. CO $\mathrm{CO}_{2}$ Emissions From Fuel combustion, International Energy Agency (IEA) , 2015.

[13] H. S. Kheshgi and R. C. Prince, "Sequestration of fermentation $\mathrm{CO}_{2}$ from ethanol production," Energy, vol. 30, no. 10, pp. 1865-1871, 2005.

[14] M. Muratori, B.-A. Schuelke-Leech, and G. Rizzoni, "Role of Residential Demand Response in Modern Electricity Markets," Renewable and Sustainable Energy Reviews, vol. 33, no. 0, pp. 546 - 553, 2014.

[15] The Global Change Assessment Model (GCAM) - Documentation, [Online], Available. [Online]. Available: http://jgcri.github.io/gcam-doc/index.html

[16] J. F. Clarke and J. A. Edmonds, "Modeling energy technologies in a competitive market," Energy Economics, vol. 15, pp. 123-129, 1993.

[17] M. Wise, K. Calvin, A. Thomson, L. Clarke, B. Bond-Lamberty, R. Sands, S. J. Smith, A. Janetos, and J. Edmonds, "Implications of limiting $\mathrm{CO}_{2}$ concentrations for land use and energy," Science, vol. 324, no. 5931, pp. 1183-1186, 2009.

[18] K. Calvin, M. Wise, P. Kyle, P. Patel, L. Clarke, and J. Edmonds, "Trade-offs of different land and bioenergy policies on the path to achieving climate targets," Climatic change, vol. 123, no. 3-4, pp. 691-704, 2014.

[19] A. M. Thomson, K. V. Calvin, S. J. Smith, G. P. Kyle, A. Volke, P. Patel, S. Delgado-Arias, B. Bond-Lamberty, M. A. Wise, L. E. Clarke et al., "RCP 4. 5: a pathway for stabilization of radiative forcing by 2100," Climatic Change, vol. 109, no. 12, pp. 77-94, 2011.

[20] D. P. Van Vuuren, M. G. Den Elzen, P. L. Lucas, B. Eickhout, B. J. Strengers, B. van Ruijven, S. Wonink, and R. van Houdt, "Stabilizing greenhouse gas concentrations at low levels: an assessment of reduction strategies and costs," Climatic Change, vol. 81, no. 2, pp. 119-159, 2007.

[21] R. H. Moss, J. A. Edmonds, K. A. Hibbard, M. R. Manning, S. K. Rose, D. P. Van Vuuren, T. R. Carter, S. Emori, M. Kainuma, T. Kram et al., "The next generation of scenarios for climate change research and assessment," Nature, vol. 463, no. 7282, pp. 747-756, 2010.

[22] IPCC, "Climate Change 2014: Mitigation of Climate Change. Contribution of Working Group III to the Fifth Assessment Report of the Intergovernmental Panel on Climate Change [Edenhofer, O., R. Pichs-Madruga, Y. Sokona, E. Farahani, 
S. Kadner, K. Seyboth, A. Adler, I. Baum, S. Brunner, P. Eickemeier, B. Kriemann, J. Savolainen, S. Schlömer, C. von Stechow, T. Zwickel and J.C. Minx (eds.)]," 2014.

[23] S. Fuss, J. G. Canadell, G. P. Peters, M. Tavoni, R. M. Andrew, P. Ciais, R. B. Jackson, C. D. Jones, F. Kraxner, N. Nakicenovic et al., "Betting on negative emissions," Nature Climate Change, vol. 4, no. 10, pp. 850-853, 2014.

[24] V. Heck, D. Gerten, W. Lucht, and L. R. Boysen, "Is extensive terrestrial carbon dioxide removal a "green" form of geoengineering? a global modelling study," Global and Planetary Change, vol. 137, pp. 123-130, 2016.

[25] D. L. Sanchez and D. M. Kammen, "A commercialization strategy for carbon-negative energy," Nature Energy, vol. 1, p. 15002, 2016.

[26] U.S. Department of Energy - Energy Information Administration, Updated Capital Cost Estimates for Utility Scale Electricity Generating Plants, April 2013. [Online]. Available: http://www.eia.gov/forecasts/capitalcost/pdf/updated_capcost.pdf

[27] U.S. National Renewable Energy Laboratory (NREL), 2015 Standard Scenarios Annual Report: U.S. Electric Sector Scenario Exploration, 2015, [Online], Available. [Online]. Available: http://www.nrel.gov/docs/fy15osti/64072.pdf

[28] Black and Veatch for U.S. Department of Energy - National Renewable Energy Laboratory (NREL), Cost and Performance Data for Power Generation Technologies, 2012. [Online]. Available: http://bv.com/docs/reportsstudies/nrel-cost-report.pdf

[29] M. Ramage and J. Katzer, "Liquid transportation fuels from coal and biomass: technological status, costs, and environmental impacts," America's Energy Future Panel on Alternative Liquid Transportation Fuels, National Research Council, 2009.

[30] D. Humbird, R. Davis, L. Tao, C. Kinchin, D. Hsu, A. Aden, P. Schoen, J. Lukas, B. Olthof, M. Worley, D. Sexton, and D. Dudgeon, "Process design and economics for biochemical conversion of lignocellulosic biomass to ethanol: diluteacid pretreatment and enzymatic hydrolysis of corn stover," Prepared for U.S. Department of Energy National Renewable Energy Laboratory (NREL), 2011. [Online]. Available: http://www.nrel.gov/docs/fy11osti/47764.pdf

[31] A. Dutta, M. Talmadge, J. Hensley, M. Worley, D. Dudgeon, D. Barton, P. Groenendijk, D. Ferrari, B. Stears, E. Searcy, C. Wright, and J. Hess, "Process design and economics for biochemical conversion of lignocellulosic biomass to ethanol: Thermochemical pathway by indirect gasification and mixed alcohol synthesis," Prepared for U.S. Department of Energy National Renewable Energy Laboratory (NREL), 2011. [Online]. Available: http://www.nrel.gov/docs/fy11osti/51400.pdf

[32] Z. Haq, "Advanced biofuels cost of production," Prepared for U.S. Department of Energy Biomass Program, 2012. [Online]. Available: https://www1.eere.energy.gov/bioenergy/pdfs/aviation_biofuels_haq.pdf

[33] R. P. Anex, A. Aden, F. K. Kazi, J. Fortman, R. M. Swanson, M. M. Wright, J. A. Satrio, R. C. Brown, D. E. Daugaard, A. Platon et al., "Techno-economic comparison of biomass-to-transportation fuels via pyrolysis, gasification, and biochemical pathways," Fuel, vol. 89, pp. S29-S35, 2010.

[34] M. Muratori, C. Ledna, H. McJeon, P. Kyle, P. Patel, S. H. Kim, M. Wise, H. S. Kheshgi, L. E. Clarke, and J. Edmonds, "Cost of Power or Power of Cost: a U.S. Modeling Perspective," Renewable and Sustainable Energy Reviews, vol. Under Review, no. 0, 2016.

[35] J. J. Dooley and R. T. Dahowski, "Large-scale US unconventional fuels production and the role of carbon dioxide capture and storage technologies in reducing their greenhouse gas emissions," Energy Procedia, vol. 1, no. 1, pp. 4225-4232, 2009.

[36] J. J. Dooley, S. H. Kim, J. A. Edmonds, S. Friedman, and M. Wise, “A first order global geological $\mathrm{CO}_{2}$ storage potential supply curve and its application in a global integrated assessment model," Pacific Northwest National Laboratory Joint Global Change Research Institute, 2003.

[37] E. S. Rubin, J. E. Davison, and H. J. Herzog, "The cost of $\mathrm{CO}_{2}$ capture and storage," International Journal of Greenhouse Gas Control, vol. 40, pp. 378-400, 2015.

[38] H. S. Kheshgi, R. B. Hirsch, M. E. Parker, G. F. Teletzke, and H. Thomann, "Carbon dioxide capture and storage: perspective on cost and economics," in Proceedings of the 2012 World Gas Congress. IIG, 2012.

[39] U.S. Energy Information Administration (EIA), State Energy Data 2013: updates by Energy Source, 2013. [Online]. Available: http://www.eia.gov/state/seds/sep_fuel/html/pdf/fuel_pr_ww.pdf

[40] D. McCollum, N. Bauer, K. Calvin, A. Kitous, and K. Riahi, "Fossil resource and energy security dynamics in conventional and carbon-constrained worlds," Climatic change, vol. 123, no. 3-4, pp. 413-426, 2014.

[41] Better Use of Biomass for Energy, International Energy Agency (IEA) , 2010.

[42] Chum, H. and Faaij, A. and Moreira, J. and Berndes, G. and Dhamija, P. and Dong, H. and Gabrielle, B. and Goss Eng, A. and Lucht, W. and Mapako, M. and Masera Cerutti, O. and Mclntyre, T. and Minowa, T. and Pingoud, K., Bioenergy. In IPCC Special Report on Renewable Energy Sources and Climate Change Mitigation [O. Edenhofer, R. Pichs-Madruga, Y. Sokona, K. Seyboth, P. Matschoss, S. Kadner, T. Zwickel, P. Eickemeier, G. Hansen, S. SchlÃ Imer, C. von Stechow (eds)], 2011.

[43] B. Metz, O. Davidson, H. De Coninck, M. Loos, and L. Meyer, "IPCC special report on carbon dioxide capture and storage. Prepared by Working Group III of the Intergovernmental Panel on Climate Change," IPCC, Cambridge University Press: Cambridge, United Kingdom and New York, USA, vol. 4, 2005.

[44] H. Herzog and J. Eide, "Rethinking ccs-moving forward in times of uncertainty," Mining Report, vol. 149, no. 5, pp. 318-323, 2013. 